|| ISSN(online): 2589-8698 || ISSN(print): 2589-868X ||

International Journal of Medical and Biomedical Studies

Available Online at www.ijmbs.info

Volume 3, Issue 2; February: 2019; Page No. 50-53

PubMed (National Library of Medicine ID: 101738825)

Index Copernicus Value 2017: 40.03

\title{
TO STUDY THE FACTORS INFLUENCING ANEMIA AMONG ADOLESCENT GIRLS
}

\author{
Garima Gupta $^{1}$, Pinky Dhariwal ${ }^{2}$ \\ ${ }^{1}$ MBBS, SMS Medical College, Jaipur \\ ${ }^{2}$ MD. Pathology, Consultant in Ram Snehi Hospital Bhilwara
}

Article Info: Received 22 January 2019; Accepted 15 February. 2019

Cite this article as: Gupta, G., \& Dhariwal, P. (2019). TO STUDY THE FACTORS INFLUENCING ANEMIA AMONG ADOLESCENT GIRLS. International Journal of Medical and Biomedical Studies, 3(2).

DOI: https://doi.org/10.32553/ijmbs.v3i2.94

Address for Correspondence: Pinky Dhariwal, MD. Pathology, Consultant in Ram Snehi Hospital Bhilwara

Conflict of interest: No conflict of interest.

\begin{abstract}
Background: The prevalence depends on the socio demographic conditions, food intake patterns, cultural beliefs and is quite heterogeneous across the country

Methods: This was cross-sectional study. A total of 100 girls were interviewed and were investigated for their Hemoglobin concentration. A predesigned and pretested schedule was used to collect the information about the participants.

Results: The association between SES and anemia was found statically significant. The association between mother education and anemia was also found statically significant but association between type of family and anemia was also found statically Insignificant.

Conclusion: Nutrition education along with nutritional supplementation and iron folic acid tablets should be provided to all girls.
\end{abstract}

Key Words: Adolescent Girls, Anaemia, Socio-Demographic Characteristics, Education

\section{Introduction:}

Adolescence age group bridging childhood and adult life, marks the transition in social role with increasing potential to shape the country's economic prospects and bring about change within the community. Adolescents to include persons aged $10-19$ years. ${ }^{1}$

There are about 1.8 billion adolescents globally today and $90 \%$ of the adolescent population is reported to be living in developing nations. ${ }^{2}$ Even though adolescent age group is considered as relatively healthy period, increasing number of studies are proving that it is a great misconception. The adolescents are at risk of many diseases and nutritional disorders especially anemia is a major adolescent
morbidity.

The prevalence of anemia is reported to be ranging between $30 \%$ to as high as $68.8 \%$ as reported by various community based studies across India. 4 This burden is comparatively similar and in some cases higher than prevalence reported from other developing countries. ${ }^{5}$

The prevalence depends on the socio demographic conditions, food intake patterns, cultural beliefs and is quite heterogeneous across the country. ${ }^{6}$

In spite of the number of interventions undertaken to combat anemia, its prevalence continues to be high in the adolescent 
population. In the light of the rapid sociodemographic transition in the country, many of the adolescents are living in urban areas. Even though there were many studies conducted in India on prevalence of anemia in adolescent age group, studies focusing on urban adolescent females are very few. Considering the fact that majority of the urban adolescents are enrolled for their education in the private sector, they are quite often left of the government run prevention and control programmes.

\section{Material and methods:}

This was cross-sectional study. All the adolescent girls studying in standards 9 th $-12^{\text {th }}$ class who were given consent to hemoglobin estimation were included in the study. The girls $\geq 20$ years, and those suffering from any chronic disease were not included in the study. A total of 100 girls were interviewed and were investigated for their Hemoglobin concentration. A predesigned and pretested schedule was used to collect the information about the participants.

Haemoglobin was estimated by the cyanmethaemoglobin method. It is measured in terms of $\mathrm{g} / \mathrm{dl}$. Capillary blood was drawn by finger prick method. Cuvette tube was pre-filled manually with Cyanmethhemoglobin reagent. It was incubated for 5 minutes and finally readings were noted. For every sample a blank tube was placed in the machine to avoid the error or check the accuracy.

\section{Results:}

The mean age of adolescent girls were $13.2 \pm 2.3$ years and mean $\mathrm{Hb}$ level was $10.1 \pm 2.1 \mathrm{gm} / \mathrm{dl}$.

Table 1: Base line data

\begin{tabular}{|l|l|}
\hline $\mathrm{Hb}$ level $(\mathrm{gm} / \mathrm{dl})$ & $10.1 \pm 2.1 \mathrm{gm} / \mathrm{dl}$ \\
\hline Age (years) & $13.2 \pm 2.3$ years \\
\hline
\end{tabular}

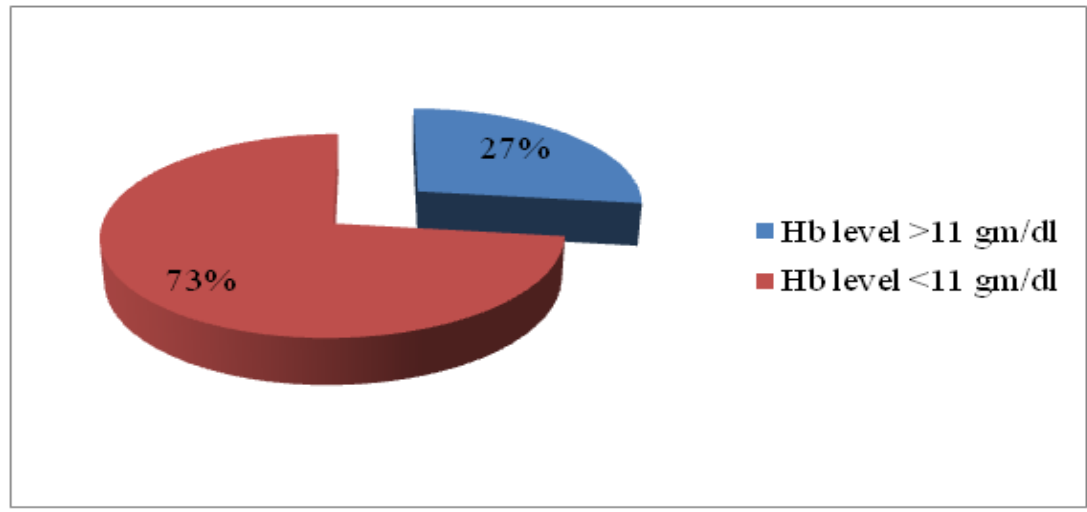

Table 2: Association between socio-demographic profile and anemia

\begin{tabular}{|l|l|l|l|}
\hline $\begin{array}{l}\text { Socio-demographic } \\
\text { variable }\end{array}$ & $\begin{array}{l}\text { Anemia present } \\
(\mathrm{n}=73)\end{array}$ & $\begin{array}{l}\text { Anemia absent } \\
(\mathrm{n}=27)\end{array}$ & p-value \\
\hline $\begin{array}{l}\text { Socio-demographic } \\
\text { class }\end{array}$ & & & \\
\hline I & 1 & 2 & 0.001 \\
\hline II & 4 & 8 & \\
\hline III & 10 & 12 & \\
\hline IV & 58 & 5 & \\
\hline Type of family & & & \\
\hline Joint & 16 & 8 & 0.071 \\
\hline Nuclear & 57 & 19 & \\
\hline
\end{tabular}




\begin{tabular}{|l|l|l|l|}
\hline Mother education & & & \\
\hline Illiterate & 18 & 1 & 0.001 \\
\hline Primary & 22 & 3 & \\
\hline Secondary & 13 & 4 & \\
\hline Graduate & 20 & 19 & \\
\hline
\end{tabular}

Most of the girls i.e.97 (97\%) belonged to the socioeconomic class II, III,IV. The association between SES and anemia was found stastically significant. The association between mother education and anemia was also found stastically significant but association between type of family and anemia was also found stastically Insignificant.

\section{Discussion}

The National Pilot Programme on Control of Micronutrient Malnutriton launched in 1995 by the Ministry of Health and Family Welfare $(2000)^{7}$ reported point prevalence of anaemia in various age groups and found to be high in both sexes. In adolescents, the prevalence rate of mild and moderate anaemia was also very-very high i.e., 65.8 per cent in boys and 81.3 per cent in girls with severe anaemia of boys 3.8 per cent and girls $6.0 \%$.

In the present study, the overall prevalence of anaemia was 73.00 per cent in adolescent girls, which is higher than the prevalence (34.5\%) reported by Rawat et al $(2000)^{8}$ among adolescent girls in rural area of Meerut. But it is reported to be low as compared to 73.7 per cent reported by Misra et $\mathrm{al}^{9}$ and multicentric study in 3 regions of India (Mumbai, Gujarat and Delhi) ${ }^{10}$ which showed anaemia prevalence as 62 65 per cent, 57-65 per cent and 48-50 per cent respectively in adolescent girls.

Reverse association was seen between socioeconomic status and prevalence of anaemia in adolescent girls; lower the socio-economic status, and higher the prevalence of anaemia in our study. Thavraj and Reddy $(1985)^{11}$ noted iron deficiency among 20 per cent of healthy nonanaemic high income group children. Hence it is evident that a significant proportion of the apparently healthy children belonging to the higher socio-economic class suffer from overt anaemia and may have latent iron deficiency anaemia if not anaemic. The possible reason for this could be the poor bio-availability of iron in Indian diet. Kapoor and Aneja $(1991)^{12}$ noted prevalence of anaemia in 47 per cent of adolescent girls belonging to high socioeconomic group and 56 per cent in lower middle class. In a study by Vasanthi et al $(1994)^{13}$, it was found that mean $\mathrm{Hb}$ showed a rising trend with improved socioeconomic status and most of the children belonging to lower socio-economic status were anaemic. This may be because of better availability of high quality of food for children with better socio-economic status.

The association between mother education and anemia was also found stastically significant in our study. Rawat et al ${ }^{8}$ also reported that the prevalence of anaemia was more in adolescent girls who are illiterate (42.2\%) and just literate $(40.3 \%)$ mothers as compared to educated mothers. It shows a significant correlation between the level of parental education and girl's education. Particularly, the education of mothers is a significant factor for girl's education.

\section{Conclusion}

Nutrition education along with nutritional supplementation and iron folic acid tablets should be provided to all girls.

\section{References}

1. UNFPA. Adolescent and Youth Demographics: A brief overview Available at: http://www.unfpa.org/resources/adolescent and-youthdemographicsa-brief-overview.

Accessed on 23 November 2017.

2. UNFPA. The Power of 1.8 Billion: Adolescents, Youth and the Transformation of the Future 2014 Available at: http://eeca.unfpa.org/en/publications/ state-world-population-2014-report. 
3. WHO. The global prevalence of anaemia in 2011. Geneva; 2015.

4. Agarwal KN, Agarwal DK, Sharma A, Sharma K, Prasad K, Kalita MC, et al. Prevalence of anaemia in pregnant \& lactating women in India. Indian J Med Res. 2006;124(2):173-84.

5. Chaudhary SM, Dhage VR. A study of anemia among adolescent females in the urban area of nagpur. Indian J Community Med. 2008;33(4):243- 5.

6. Ghosh R, Bharati P. Haemoglobin status of adult women of two ethnic groups living in a peri-urban area of Kolkata city, India: a micro-level study. Asia Pac J Clin Nutr. 2003;12(4):451-9.

7. Control of Nutritional Anemia with special Reference to Iron Deficiency: WHO Tech.Rep.Ser.No 580; 1975.

8. Rawat C.M.S. (2000): An Epidemiological Study of Anaemia in Adolescent Girls in the Rural Area of Meerut. (Thesis submitted for
M.D. in Community Medicine, C.C.S. University, Meerut).

9. Misra et al:Study of Physical Growth, Anaemia and Reproductive Health Status of Adolescent Girls in Urban Poor (Delhi) published by MAMTA Health Institute for Mother and Child.

10. IDA Control - A Public Health Programme Priority (1998) Shiela C Vir, UNICEF, Proc, Nutri. Soc. India Vol $47:$ 45-73.

11. Thavraj V.K. and Reddy V. (1985) Serum Ferritin in Healthy School Children. Indian Paed, 22:51-52.

12. Kapoor G. and Aneja S. (1992) Nutritional Discorders in Adolescent Girls, Indian Paed. 29: 969-973.

13. Vasanthi Cr. Pawashe, A.B. Susie H, Sujatha T. and Ramesh L. (1994) Nutritional Status of Adolescent Girls from Rural and Urban Slums. Indian Paed (31):127-132. 